\title{
Doctor-Mindedness, Substance Abuse and Addiction Including Alcoholism and Hero-Minded Gung-Ho Pop-Media Culture Regarding the Industrialisation of the Health System and A Media Industry for Profit Promoting Illness Whilst Arguing Recovery Activation and the Holistic Role of the Media Industry
}

\author{
Tumanako William Hongi Pugh* \\ Mental Health Community Leader and Role Model for the Peer Support Community, Australia
}

*Corresponding author: Tumanako William Hongi Pugh, Mental Health Community

Leader and Role Model for the Peer Support Community, Australia.

Received Date: May 04, 2019

Published Date: May 31, 2019

\section{Abstract}

Addiction is a complex health issue that more than likely will eventually lead to an early death or serious health issues and/or serious mental health issues if unarrested by neither taming each of our own individual and collective ritualistic arrangements in regards to how we, each of our own selves, view addiction, consumption of a product, substance abuse, chemical toxicity, body health, mental illness and the mind state yet is influenced primarily by each of our own family engagements, activities and primary imprinting of family values and/or principles, if any, upon the young and therefrom influence and affect working roles regarding social agreements and the particular drug of choice we use [1].

In that if such drug-like pill popping-like addictions of addictive behaviour, what such an addiction is, goes unchecked and un-remedied such issues may flair up time and time again, over and over again to thereby impair ones' well-being, perception and thoughts therefore altering each of our own lives around each of our own selves and addictions collectively as a human race gathered around drug institutionalism impairing society by impaired Doctors providing instant relief rather than holistic cures nor otherwise real wholesome preventative measures gathered around full health driving overall well-being and empowered lives without illness whilst only promote the illness and the over-looking of key underlying issues that present themselves at times of change affecting physical, mental, emotional and spiritual realities of patients and clients over time whilst altering their patient lives altogether.

That substance abuse, alcoholism and the intrinsic behaviours that present themselves whilst inebriated and/or under the influence of substances will definitively impair each of our own individual realities to therefore make impaired decisions without true insight for each of our own selves and others entirely yet meanwhile places each of our own lives at risk whilst may also place the lives of others at risk altogether including children.

That such behaviour presented relate to the psychology of drug addiction and the nature of substance abuse, alcoholism and mocking-like behaviour yet meanwhile explains also the nature of a gung-ho industry and the incomplete encapsulation of illness and an unhealthy Earth in regards to the portrayal of heroism and heroine acts of sacrifice portrayed in the media, on television and within cinematography mediums [2].

That due to the nature of media and the portrayal of illness, mental illness and yet meanwhile also the placement of drugs and addiction in each of our own lives as children affects each of our own realities and promotes the ill-behaviour of impaired viewpoints and realities thereon in, therefore, promotes illness, death and disease within families and society as a whole.

In that such behaviours expressed herein are but acts re-enacting the presentation of relative information being incomplete and without truth related to the heavens, earth and hell yet relate also to the incomplete evidence presented by inhumane consciousness imprinting upon the minds of the young and finally to act out from the power of personal choice to say "no" or otherwise the free will to concede and say "yes", yet, herein being made as being entirely contained complete by observations over time.

Yet finally concluding that recovery is indeed possible that surgeons know that hope is always present no matter how small such hope is held onto by surgeons and patient yet as hope is always available hope can manifest itself to alter the nature of surgery, pain and the lives of others altogether as one. 
In that as life is life and there is a hope for all mankind to be greeted to their maker so be it!

That there is indeed a hope in recovery to recover well fully enlivened and well- balanced, fully well and healthy, fully clean and obstinate and fully empowered with hope thereon upon the decision made primarily and first step to seek recovery and break the cycle of deterioration into death due to addiction by a connection with others felt true and the connections with the All-Creator and the self as being altogether real.

\section{Doctor-Minded Impairment of Ill-Reputed Doctors}

\section{Impairing Individuals Regarding Medicating Society Driving the Global Drug Institutions}

That even clinicians, doctors and psychologists may even be impaired in regards to each of their own judgements calls and insights to only provide band aid like solutions and remedies to treat patients and clients with a medication that masks symptoms to then flare up again in that such symptoms maybe underpinning a deeper core issue that has gone untreated and unmasked whilst such clinicians regard medication and band aid like treatments to treat clients with such un-holistic methods with unwholesome value put to such un-holistic treatments.

Therefore, ignore the truly underlining symptoms yet disregard the true value put to healing and remedial therapy due to revolving door-like surgeons and doctors providing hospital beds and medications without any accountability in each of their own conduct of ill-repute regarding medicating society and the ill-treatment of people's bodies to provide surgery that does not entirely heal whatsoever at all.

In that such treatments only offer a quick fix to only serve and usher patients and clients in and out of the service provider doors to but then impact further upon such individuals by valuing pays of clients in servicing before real holistic remedies yet providing treatments for addicted doctor shopping clients with addictive personalities and behavioural types of impairment.

That such doctors and treating clinicians, physicians and psychologists disregard the real issue that is underpinning such individuals within their care entirely regarding medication and pain relief as treatment rather than being a cure nor are they, said doctors willing to treat patients by preventative measures of holistically more valuable remedies rather than band aid like treatments offering pill shopping.

Whilst further impacting upon such client's health by creating an addiction and medicated resource to but sustain such a pain reduction and a small value put to longevity and life-long experience of overall well-being such as holistic treatments of value treating such individuals fully from a health, mental health and nutritional perspective rather than just providing medication entirely and solely alone.

That such professionals are responsible for the long life duration and longevity of clients meanwhile are responsible for promoting overall well-being, health, mental health and wellness entirely alone rather than just providing patients with band aid like remedies and treatments of treating illnesses thereby medicating society by also providing such Professionals with large sums of money to then sustain each of their own longevity and life span for the long term of which defeats the purpose of Medicine and Psychology altogether.

In that not only should doctors be held responsible for medicating society but also that drug companies are entirely responsible for medicating humanity whilst not valuing holistic treatments without needing nor requiring medication of which is predominantly a doctor-like mentality and personality disorder comparable to any other regarding the views they hold true to themselves as valuing health, mental health, well-being and wellness as holding primarily in highest esteem each their own individual well-being of clinics and companies wealth of well-being, health and money entirely unto themselves alone by gaining and obtaining a piece of the pie.

Yet meanwhile treating clients as being a resource for a medicated illness and disease rather than a complete and whole individual capable to heal themselves by being well-equipped to do so by being armed with knowledge regarding educating themselves around their illness yet providing themselves with the much needed care they need to contain the illness, heal the illness given more holistic treatments such as Eastern Medicine and Naturopathy whilst meanwhile providing support for such clients to promote and sustain each of their own healing needs to naturally heal given their requirements to do so.

Gathered around knowing what the body needs to heal by providing insight into each of their own tailored well-being by presenting information willingly placed upon the institution and fraternity of medicine armed with knowledge whilst knowing what the body needs and what it is truly telling us by a sense of selfknowingness. In that such doctors treat patients and clients as a sickness or illness presenting in their treating rooms to but provide themselves, doctors, with monies and pays to then regard the drug related companies in highest esteem and therefore institutionalizing patients at will, to then end in death, whilst regarding each of their own health alone, as doctors and the medical institution it is.

To but only suffice the reliance upon the health industry whilst sustaining the feeding upon the health industry to therefore only medicate society holistically impairing humanity towards one of addiction to medication and the ever reliance upon such un-holistic treatments gathered around a dying young, sick and afflicted, ill and unhealthy, mentally ill and negatively impacted, addicted and/ or otherwise an impaired human race gathered around doctor shopping and instant relief from pain and ills due to the nature of instant gratification and instant pain relief remedies to be sustained and met.

Of which such an impaired perspective is but a blight of ignorance upon the Health System to only but impair lives by 
addiction to medication-based treatments that do not even treat the underpinning core issues that such patients and clients present with.

Furthermore, that these industries, such as the health industry, drug companies, alcohol suppliers and entertainment industries are but prostituting themselves for money and pay to but impair peoples' lives through constant addiction to either substances, clinical advice, alcohol and pornography. Which does not provide any relief from any issue regardless of any substantiated promise given by such industries to provide all individuals with instant gratification, living proof and satisfaction meanwhile takes livelihoods, monies and pays to but only suffice each of their own over enlarged and inflated dollars to then claim lives and take them to the grave regardless of whether they are poor or rich without accountability in isolating either and all whilst regarding life as being just the treatment of illnesses required to service for enlarged pays.

Of which such industries do not put a value to life other than the dollar value a of gross domestic product of each their own industries and companies alike by viewing people as dollar signs rather than lives of wholeness, completeness, oneness and absoluteness as being a whole person and complete individual capable of healing themselves if applying themselves in the right way to do so.

And therefore such an industry may provide more holistic treatments and remedies would apply to giving correct treatments such as education, empowerment, hope and holistic treatments such as physio, chiropractor remedial treatment, naturopathy, acupuncture, relaxation, meditation, mindfulness, yoga and western treatments of observation, gentle guidance, holistic support, blood screening and counselling, non-judgement, neutrality, non-dualism, empathy, sharing of common experiences in commonality and finally having and engaging in compassion for such clients and patients.

To but recover well, live full and enlivened lives of wholesomeness and wellness whilst remaining fully alive rather than dying of an illness, sickness and impairment and "yes" a possible remedial medication with accountability attached to the medical fraternity.

Whilst also promoting a lessor use for medication and therefore remaining at all times responsible for the treatment of clients whilst upholding all value put to each of their own conduct and affairs relating to the medication plans and treatment availability of tablets used by either themselves, each of their own clients or otherwise family members rather than just treating clients utilizing a revolving door-like surgery and money acquisition providing a paid service for a job seemingly well done. To prescribe medication sparingly but only for real life solutions whilst remaining themselves, such services and industries, as being role-models and exemplary members of the community and society as a whole, therefore, contributing to the positive health and the increasing of well-being related to the lives of others and thereby contributing to society as a whole, within educational institutions and educating those disenfranchised or otherwise up and coming young minds of the youth.

Thereby empowering all communities and peoples to recovery and hope of value put to themselves, such peoples as doctors are and the empowerment of the arts that they engage in doctor-like attributes of wholesome value, education, hope, health, mental health, well-being and wellness rather than just prescribing another pill or tablet remedy of band aid like treatments in regards to treating illnesses, sicknesses or ill-health from a position of medicating society by rather providing treatments that regard holistic well-being, mental health, remedies of value and a better application of Medicine of which wholesomeness, wonder and joy to the medical fraternity and the health industry rather than just primarily medicated resources.

Addiction and its' Relationship with Mental Illness and an Impaired Viewpoint of Reality Regarding such issues as the Law and how such Individuals View Themselves yet also Explaining the Nature of Hope in Recovery Activation into Abstinence

Addiction is comparable to mental illness yet is a determinant determining mental illness and impairment yet meanwhile is not entirely the major determining factor but rather as being a contributing factor determined to be one individual by connectivity to a collective of substance abusers being impacted by substance use and impaired by clouded judgement and impaired decision-making processes due to such an impaired and clouded state of mind with clouded judgement calls and poor decision making processes due to the nature of addiction and substance abuse of which is such an uncontrollable addiction therefrom yet is that which takes hold of such individuals whilst meanwhile controls their every desire to sustain each of their own individual drug use and substance abuse regardless of wasted health and poorer outcomes relating to early death, addiction and impairment.

Of which also relates to how such individuals view law enforcement agencies and each of their own seemingly so called Angelic Godly ways or otherwise their own incomplete viewpoints of the heavens by entertaining impaired belief systems regarding heaven, hell and the earth-bound realm yet how such individuals view the law as unnecessary whilst view each of their own behaviour and attitudes as acceptable whilst such individuals are neither desirous for change and recovery nor the altering of each of their own individual behaviours, viewpoints and realities due to engaging predominantly in drug abuse and the use of doctorshopping pill-popping attitudes more so than any other type of addiction.

In that neither of such views are correct in that by arguing that if such individuals would highly regard both pillars of the law, god's law and man's law regardless of where each is placed and then value could be brought to such addictive tendencies and behaviours to then learn to value the Law and cease such behavioural traits, attributes and addictions gathered around abstinence, lawfulness 
and hope to therefore arrest each of their own individual addictions and fully recover well, enlivened, fully rounded, balanced and healthy with each of their own mental health in highest concern coupled with health driving mechanisms of well-being and wellness.

In that by simply regarding law officers as scum although regarding each of their own behaviour as being acceptable as claiming to be angelic of which is but a contradiction in that neither is so and so as a god-like being does not regard nor allow a toxicity of chemicals, alcohol nor drugs to run prevalent through our blood stream and/or our bodily functioning systems of nervous system and operation of the physical vessel, soul and spirit that by assumption toxicity of substance use is against Gods' Law.

That by comparison to healthy minded states of consciousness, substance abusers have impaired belief systems in that some determine demon worship, Atheism and devil worship as being each of their collective beliefs due to how they have been ill-treated when young by religious institutions and how they themselves view life, religion, god, the devil and man due to being impaired by unwholesome religious self-righteous priests impacting upon the young otherwise self-righteous parents acting in piety towards each of their own children by demands placed upon themselves and family as a whole unit due to such a religious hypocrisy.

In that also the self-sustained self-maintenance of each of our own emotional and mental capacity to engage with others in compassionate means yet meanwhile sustaining emotions of wellbeing being regarded valuable whilst neither is to be considered as a possible option for substance abuse users in that such individuals serve only the drug they desire for yet themselves alone whilst neither serve god alone nor others altogether whatsoever at all yet substantiate such beliefs to be true of which is a seriously impaired reality regarding drug addiction and addictive personalities yet meanwhile is the self-maintenance of one's life gathered around drug institutional drug use and abuse, drug addiction and drug dealing.

Furthermore that such individuals are also impaired to then make sound judgement calls for themselves regarding each of their own well-being and better management of each their own lives, livelihood and monies to be able to obtain such monies and possessions within lawful means to do so appropriately in accordance with law rather than turning to unlawful means, unlawful acts, immoral behaviour and unlawful, immoral mechanisms to provide for each their own monies.

Yet substantiate each of their own individual and collective drug addictions by one gathered around co-dependency to then only be but a slave and master to each of their own chemical toxicity and addictive personalities therefore such addictions go unchecked, untreated, unarrested and untamed therefore impair such individuals entirely to then neither make sound decisions for each their own benefit on their own behalf in respects towards each of their own livelihoods entirely nor with respect given to the wellbeing of children nor others entirely altogether also. Whilst neither can such individuals sustain each of their own individual well- being, health nor mental health without assistance of which only sustains the continual spiral into an early death yet a life of possible impairment and addiction without arresting such a debilitating an illness yet meanwhile impacting negatively upon all others in society due to presenting such a substantiated risk to themselves and others as one due to having a completely clouded and impaired mind being clouded by such drug use and abuse being unarrested.

In that such individuals are but slaves to their own devices, drug addictions and personality types, behaviours and disorders as being entirely impaired and incapable in making considerable positive and powerful choices for themselves yet are incapable in contributing to society whilst such addictions go unarrested and unchecked, untamed and un-remedied as they predominantly do so desire to contribute back to society indeed yet also furthermore do indeed desire to achieve abstinence as one people yet are but fallen angels as disgraced individuals impaired by drug addiction, institutionalization and recidivism yet furthermore there is hope that vision may return to provide clarity, insight and sight may be restored to therefore abstain, surrender, relinquish control, arrest each of their own illness with addiction, repair the damage done to the mind, body, soul and spirit and finally heal and restore health, mental health, well-being and wellness as one.

That furthermore a type of drug addiction and personality type of mentality such as a neuroses [3] and neurotic behavioural type of personality type exists of which are regarded as being possibly a drug addict-like behaviour of an addictive personality type yet entirely are very highly intelligent individuals engaging in each of their own arts of a nature of each their own self-sustaining maintenance thereof as viewing themselves as being rather highly intelligent of which they are indeed whilst fixated upon vast tomes of knowledge, information and respective understandings accumulated over time.

Regarding each of their own complete understanding of such tomes yet engage in communication exercises gathered around story-telling whilst arguing the truth with arguments made available to themselves by such vast consumption of thought and knowledge engagements and well-developed discussions focusing upon such vast topics ranging from philosophy to science and sociology whom regard such arguments as being stated facts of which maybe so yet such argumentative individuals are highly developed individual's with highly developed minds and arguments related to each of their own highly active and energised lifestyles by engaging with many peoples yet are rather not considered to be a delusional type of personality and behaviour such as Schizophrenia.

And so are people of fixation upon such topics relative to such individuals' perception and viewing of relative information of interest to themselves and others, therefore in consumption of such information over time whilst regard themselves as being highly intelligent and articulated individuals of vast amounts of knowledge and wisdom, of which as previously stated is entirely true yet meanwhile furthermore are highly intellectual beings of much intellect of wealth of which is indeed true also. 
In that even so as stating that such individuals may even enter a melt-down like state, smelting each of their own core matrix as if entering the last stages of their final living existence. That these types of individual's enter smelting and melting-down properties that such individuals are severely impaired by each their own either drug addiction and/or considerably comparable mental illness as one.

Yet smelting each of their own individual lives by a process of winding down each of their own lives into early death and dementia of ill-health and serious mental illness due to traumatic experiences experienced of which is related to such issues being un-resolved, unarrested and un-checked regarding such traumatic experiences brought about by substance abuse, dealership rights, impairment and the sexualisation of themselves neither being resolved whilst may be treated and kept in check yet in the final stages of melt down such individuals simply may not contain the physical vessel any longer and may discharge themselves from regular support mechanisms, check-ins with doctors and treatment plans altogether thereby spiral into deterioration due to continuing in each of their own sustained substance abuse in core melt down and then finally entering into each of their own death throes whilst possibly experiencing total and utter disenfranchisement related to homelessness yet are totally impacted by each of their own neurotic behaviour and neurosis as one.

Furthermore that such individuals may engage in drug related activity of dealership rights claiming other drug addicted individuals monies and pays whilst maintaining each of their own clientele to simply sustain such a neurotic melt-down state such as dealing to such clients and may even begin a further deterioration whilst spiralling out of control in core smelting of their own core melt-down and therefore may even then suffer from homelessness once again, of which may be more likely than not, due to the need to support themselves without repute nor continual doctor and specialist treatment whilst on the streets and homeless yet possibly also view law enforcement agencies as scum, yet view health physicians and doctors as a means of acquiring substances as drugs become the focus of their lives.

In that by doing so only continues their continual deterioration and spiral into early death by even claiming that, they, such individuals are not to blame in neither taking any personal ownership for any wrong doings nor otherwise by neither taking any personal responsibility for each their own individual actions therefore so claim that others are to blame entirely in that drugs are entirely acceptable, sex is a commodity as much as a commodity to deal with as drugs yet when are challenged become violent, aggressive, hateful and abusive.

Therefore, such individuals go about shaming and blaming others as if they, such individuals, have the god given right to do so as being each of their own individual servants and masters entirely alone as if even being contained somehow by homelessness and a continual cycle of deterioration into death does not sustain change abstinence and health at all whatsoever.
In that such a mental illness goes unchecked yet meanwhile may go unmasked, whilst possibly may go entirely untreated of which may even but only sustain each their own individual lies and delusional behaviour to be entertained entirely whilst remaining unchecked, unarrested and sustained by acts of sheer will to but maintain such self-deceit and yet each of their own individual daily needs are met simply by sheer containment of will alone due to engaging in unlawful acts of drug dealership, ill-repute, abusive behaviour regarding violence and the exclusive rights of their clientele being personal means for self-satisfaction including sexual favours from clients such men and women even friends.

In that by neither taking any personal responsibility nor personal ownership therefore such individuals will neither regard the law highly nor otherwise treat law enforcement agencies with any amount of respect nor dignity therefore such individuals may even doctor shop for medication by engaging in doctor-shopping and also may even use more than likely intravenously such medication and drug substances entirely altogether whilst only view drugs as acceptable in that all peoples have some form of addiction therefore by such an incomplete viewing platform drug use is okay.

Of which is but only reasoning with the demons that chase and haunt their everyday life by neither facing each of their own demons, devils and enemy within whilst projecting each of their own shadow selves thereby to only make excuses for their substance abuse by claiming the lessor of greater demons in that true mastery is not just mastery of the self but also mastery over our demons, devils and the enemy within that presents itself to us daily.

Yet if such an act of recovery activation is desired by such individuals that they may become a driving force for good.

Of which such drug addictions and addictive personality types impairs individuals in society entirely of which is but a blight of ignorance upon society due to the nature of society today as representing peoples, individuals and communities of consumerist wastefulness, disease and death.

To consume relatively more and more resources yet waste resources altogether also whilst impairs each of our own lives and livelihoods related to a culture of addiction and those addictive substances and/or resources determined from birth regarding family engagements and the roles we each undertake as being ritualistic in nature yet how we, each of our own selves, regard substances and addiction altogether as being impaired from birth of which promotes illness rather than health.

In that also as life is life and there is always hope for all nonetheless in that if there is hope for all and there is an endearing desire to recover and contribute back to society by setting the standard for recovery, self-education and education entirely coupled with the empowerment of hope, then therefore, there is a hope in recovery for all humanity as one of hope for all humanity to recover one individual at a time of which there is notwithstanding anything else whatsoever at all other than faith in the remedy, love for ourselves and others, love for the creator otherwise the having and holding onto hope indeed is the most essential for all mankind 
regardless of what impacts upon each of our own individual and/ or collective selves such as substance abuse and drug addiction, sickness, illness, rich or poor.

\section{Hero-like Mentalities of Alcoholic-like Tendencies Regarding Hero-Like Mentalities and Predator- Like Mentalities of Impaired View-Points of Reality Related to a Culture of a Pub-Crawling Behaviour Regarding the Promotion of Alcoholism, Alcohol Companies, Impairment, Illness, Sickness and Death yet also the Relationship of Gung-Ho-Like Heroism in Hollywood Portrayal of Heroism, Death and Suicidal Tendencies}

Furthermore, that alcoholism and drug addiction is a determining factor regarding mental illness, not entirely on its' own but rather being a contributing factor in relationship with how a client and/or patient first presents themselves to our services or admission into hospital.

That alcoholism may determine why such individuals particularly males present as being aggressive whilst intoxicated and inebriated by such brutal behaviour and behaving aggressively and therefore impact negatively upon the whole of society, family life and the community as a whole.

Due to how they, such intoxicated individuals, regard others in society as being targets to be targeted by violent alcoholic related abuse and violence in that such as those intoxicated individuals and male dominated mind sets of such men as having hero-like attitudes of non-value to then also regard women as being property of attainment to thereby engage in sexually illicit conduct whilst seemingly being as their knight in shining armour to but shout another drink or protect such seemingly sexually illicit women from another drunk at the bar or in the pub.

In that such hero-like mentalities are not to be considered valuable in that such behaviour simply starts fights and an outbreak of violence within bars to then claim of their status as being the saviour of women, as being damsels in distress. That such a mentality and hero-like behaviour is one of impaired judgement due to alcoholism.

Yet the engaging with seemingly so called sexually illicit women to but simply engage in sex with such women, making such men predatorily advancing upon harmless meanwhile seemingly distressed women, to but have sex with such women and advancing men's conquering rights and prowess as being great lovers of the loins whilst not being great lovers of the heart.

Of which such drunkenness engages also more than others predominantly in mocking behaviour more so than any other drug and addicted behaviour in society yet arms themselves with their working titles and roles with large volumes of money to simply impress women to then be loose in their morals.

In that a hero-like attitude and behaviour of mocking-like attitudes and disorder is to blame for such affairs and illicit sexual engagements with seemingly loose women.
And even to the point where sex is not implied nor given in that a man and his advances simply do not cease even when trying to bed such women and then rape ensues. That a man with hero-like attitudes preying predatorily upon harmless seemingly defenceless women are but the enactment of violent rape and unnatural bedding activities of a predator-like action enacting rape for such men to simply but impress their friends and shame the honour of a woman for simple pleasure sports of shame and rape therefore seemingly making it okay to boast of such conquers of which impairs women entirely and places them as footstools to men's unlawful and predatory behaviour and actions.

In that such men cannot simply but find a woman of value to them as being an equal and would rather be the knight in shining armour coming in to but save the poor defenceless damsel in distress and carry her off on his white horse into the sunset to never be seen again.

Of which maybe so that even death may be the result for such seemingly defenceless women going out to have a simple drink at the bar one night whilst engaging with a man that may or may not value her whatsoever at all and therefore a predator-like male approaches whom simply watches her engage with this man from across the bar. Meanwhile such a harmless and defenceless woman is unaware that such a man across the bar is watching her and because it seems that she would rather not talk to this man, she is engaged with in conversation as such a predator knows that, he simply approaches seemingly harmlessly to therefore swoop in but with only one intention to claim this seemingly defenceless damsel in distress for himself.

Which more than likely results in either rape, death or serious regret for a woman whom only wanted to have a drink on her own and would rather not get involved with any man and would've rather have liked to be left alone on her own, to her own devices and have a simple night out alone or otherwise a night out with the girls in safety whilst entertaining an open mindedness of potential possibilities regarding a simple night of fun, dancing, playfulness and revelry.

That such a hero-like mentality is but a 'Sir Lancelot Disorder' comparable to one of raping queens claiming for such so-called acts of heroism yet regard themselves as being a conqueror and king with many conquests and spoils of so-called loose women's hearts as his personal conquests, spoils and medals of self-acclaiming prestige and honour in that he has bedded many women willingly due to giving themselves to him of which maybe so and boasts that he is a king of all kings in that he is neither a King nor a conqueror, that he is but a rapist, raping queens and running them down but to commit suicide and die in despair yet on the other hand such men are but only solicitous males in that even so if rape did ensue that possibly that such a rape and rapist was never brought to light and punished by the Law as such a conqueror has much wealth and money to obtain his home, sustain his abode, acquire his toys and pay for a handsome lawyer at which time serious despair and suffering ensues for such women whom are taken advantage of due to engaging with predatory-like pub-crawling rapists. 
Therefore preying upon women in bars with a monetary value put to just simply buying such women another drink to then take them home such as being a seemingly helpless woman they then are, without indicating that sex is implied and that by doing so would then arm himself in his home and then force himself upon such an unwilling participant and furthermore obtain the reasonable services of a well-paid lawyer to but claim his innocence and then be released from his endearing judgement and court case that has then ensued.

To then claim to his friends at the bar that such a woman was but loose and she deserved what she got, of which is wrong, yet, 'no does mean no' and if it was not even indicated regardless of what was implied that such behaviour is simply put "unlawful and ill-reputed without standard nor kingdom to bear such wealth" to therefore prey upon helpless and seemingly loose-minded women entirely as one.

Furthermore in regards to alcoholism women can also be predatory as well, in that they would make out to be interested in a man and then ask for him to buy her drinks of which the man takes that as an offer to engage in sexual conduct of which such women know very well that this is not the case and that she will prey upon each drink to then leave the man penniless in despair and without hope of ever engaging with a woman in the bar, drunken and inebriated, seemingly stumbling home from a night out on the town.

To but only engage with a single woman to find true love or otherwise restore hope that the light of love may be re-ignited by engaging with other single women in bars, nightclubs and pubs only to be robbed by an armed assailant whom also watches across the bar after such a single man exits the bar, nightclub or pub or otherwise such a robber views a defenceless poor man stumbling home drunk whilst on the streets making each of their ways home.

In that as one woman has impacted upon a man's hope of ever finding true love in a bar, of which is senseless and will never happen whilst inebriated, drunken, penniless and hopeless to be but robbed by an armed assailant following a seemingly innocent night out to but only find true love, restore hope and a further passion for life yet meanwhile an adjacent woman has been impacted by a man whom only desires for a drunken night of partying, revelry and sexual solicitation of women's loose morals.

That drunken men and women are predatory pub crawlers preying upon seemingly senseless nights of drunken revelry to but engage in sex and rape or otherwise obtain a free drink and free night out without paying for a thing, neither confessing nor owning up for any ill repute and illegal behaviour of which pubs and bars promote such behaviour by promoting a drinking culture gathered around rape and ill repute in regards to only requiring another drink whether it be given to a defenceless woman and a seemingly overindulgent night of passion ending in rape or otherwise obtaining a free night out ending in robbery or most likely a drunken night of fun, games, partying, revelry and the chance of solicitations by engaging in sex with the opposite gender with loose morals, free drinks and loosened tongues of crass behaviour, mockery and boastfulness of ego projecting maniacs engaging in drunkenness without standards, kingdoms nor any sense of real responsibility other than work.

That the alcohol industry is to blame for the senseless violence of hero-like behaviour or otherwise rape and a night of revelry to obtain a woman's morals and run them through the dirt or on the other hand obtain a man's heart and be shouted a night of free drinks to then run a man's heart into the ground.

That by promoting the free acquisition of women's so-called loose morals and men's so-called desperate hearts are the result of an alcohol-based society governed around the free acquisition of a drink and the acquisition of patron's monies, heart's, mind's, bodies, soul's and livelihood as one. That also hero-mindedness of hero-like behavioural type personality disorder does also exist that are but dangerous men or women who but put lives in danger to simply but shoot first and ask questions later of which endangers lives entirely and may even cause death to such hero-like trigger happy armed individuals going into dangerous situations blazing guns.

In that a true hero is regarded as worthy and respected to risk his or her own life to save others without endangering the public or otherwise children such as racing into a blazing and smouldering inferno to save children, elderly people or animals, diving into a pool or lagoon to save a drowning person, resuscitating others whom have drowned or gone unconscious and furthermore rescuing an injured person from a wreckage or damaged vehicle otherwise rescuing individuals whom are lost.

As such individuals who do this as previously outlined are revered, honoured and respected as safe men and women rather than just a trigger-happy armed assailant going in to save others to kill all and be killed at the same time.

As such trigger-happy mentalities are but the actions of blood thirsty killers and military minded men who are mercenary, uncontrollable and armed as ex-servicemen, armed civilians and men of the public to be scrutinized or otherwise an unrestrained rogue agent enforcing his or her own justice entirely.

That such behaviour is but the enforcement of such triggerhappy individual's juridical means of being judge, jury and executioner of which are but unlawful acts altogether without consideration for groups and proper means of obtaining justice nor any consideration put to anyone else entirely of which are but a danger to themselves and others altogether as one.

In that the major contributing factor related to hero-like mentalities of hero-mindedness resulting in the negative impact regarding impairment is due to the promotion of hero-like mentalities in the movies, on television and in the media [2] otherwise the negative fallout regarding bullying, harassment and intimidation tactics of which is shown in schools and communities 
to drive a wedge between peoples and cries for help related to acts of violent retaliation perpetrated upon each of their own bullies as being the victim of bullying engaging in retaliatory violence in schools [4] due to toxic environments based around tomfoolery, mocking, belittling and scorn of disgust felt towards others entirely.

Of which such acts are responsible for the increase in criminallike behaviours and tendencies relating to the promotion of each of their own Hollywood and media moguls interests regarding cinematography and the portrayal of violence on television primarily impairing all society altogether all throughout the Earth by encouraging drug and alcohol abuse, Hollywood like impairments and gung-ho attitudes in movies, on television within the music industry and gung-ho pop culture whilst promoting criminal behaviours to therefore go neither checked nor remedied by irresponsible ill-repute without regard for humanity.

In that such an industry remains in-transparent or otherwise unaccountable yet meanwhile promotes cultural addiction, crime and hero-mindedness whilst encourages behaviours related to such a culture of addiction and criminal tendencies gathered around piracy and pirate-like attitudes as being unlawful criminals escaping punishment that the entertainment industry, actors and artists only promote to but portray an unwell, ill society suiting the A-typical Hollywood like cinema portrayal of hero-like behaviours and hero-like tendencies.

For such horrors portrayed by Hollywood media giants to but continue going unchecked, un-remedied and unmasked nor having or containing any feelings of any guilt or sense of remorse for those they imprint with Hollywood like mental illness gathered around hero-mindedness and gung-ho criminal behaviour whilst neither hold any sense of personal responsibility put to the entertainment industry and such Hollywood media moguls as one without accountability whatsoever at all.

In that the media and Hollywood would do better to serve their ratings by neither promoting addiction nor criminal behaviour related to hero-mindedness whilst promoting wellness in acquiring the vast acquisition of monies and pays by promoting positive stories of empowerment and hope.

To therefore remain only more than desirous to then obtain an accepting audience governed around well-being rather than illness, criminal behaviour, hero-mindedness and sickness by sharing stories of hope, recovery, compassion, unconditional love, self-sacrifice and empowerment by inspiring others to do likewise therefore promoting empowered lives with hope to the top position and role.

To therefore portray valuable lives and real stories regarding a complete change of heart by overcoming tragedy yet meanwhile overcoming adversity altogether whilst over-coming challenges by rising above the odds, holding onto hope and perseverance whilst meanwhile obtaining hope with self-sacrifice and unconditionally loving hearts by modelling a well-balanced, well-rounded, hopeful, brighter humanity for future generations to come by promoting and endorsing the brand of hope.
Yet to then obtain a life-long love, partner and yes meanwhile promoting a hero that risks his or her life without endangering others of which is a more valuable story to share rather than just a gung-ho like hero mentality being portrayed as a trigger-happy armed assailant going in to kill all and be killed alike.

\section{Conclusion}

Finally by totally endorsing hope and the recovery activation processes related to arresting each of our own individual and collective addictions, substance abuse, alcoholism, mental illness and impairment by a twelve step-like process of surrendering to a higher power than each of our own selves yet meanwhile relinquishing control over each of our own individual addictions whilst maintaining and holding onto hope, faith and love for one another and ourselves with full love given to a higher creative force yet also supporting one another through each of our own recovery journeys by empowering and inspiring all due to the promotion of the stories of hope in igniting change through the inspiring of hope due to such as role-modelling globally in the media, in each of our own lives, at work, at home and at play by sustaining each of our own role-modelling empowered lives with hope into health , mental health, well-being and wellness yet meanwhile sustaining each of their collective abstinence into venerable age as being endearing lives full of hope, long life, long love and happiness to support one another through the telling of the stories of hope and change, the telling of empowerment, the education of others through Artistic Ethical Values put to the media and the role-modelling with others effectively approached to empower and inspire all given a shared common experience in commonality with other's.

That by neither arresting the inherent nature of society to control humanity via the dictates of disposable consumerism and human waste by only desiring for profits of money, lives, livelihoods and illness profiting from the suffering's of others nor providing a likely remedy only promotes forced Euthanasia upon humanity without aim to recover the Earth yet promotes entirely illness, dis-ease, mental illness, sickness and death due to the nature of consumerism and control dictates to capitalise on a free market system in operation throughout the earth by economist values put to money and lives for profit.

In that only by arresting such a post-modernistic of consumerist consumerism, capitalism, control dictates of a herd mentality, pop culture and cinematography gung-ho realities through such twelve step-like mechanisms of providing a brighter outlook to promote recovery, human resilience and the ignition of change for the better transformation of the self into health, overall well-being, mental health and wellness rather than just showing images the disease of which will empower hope throughout the globe.

In that if hope is an endearing desire to achieve a goal, prize, trophy or desire for an attainment or object of desire therefore as such is the endearing definition of hope congruently by all means with hope anything is possible given the right tools, skills, education and insight to achieve each of our own wildest dreams and desires to be sustained. 
So keep on the 'Dreaming of Hope' and all that which we desire may be manifested over time with the strength and courage to stand against all odds presented and relinquish control to the Almighty Creator and surrender to a chance of fate that by destined right, perchance, we may be restored to the light of the fire of desire to ignite change once more and heal, recover and live lives full of love, life, faith and hope as one Earth, Globe and Peoples.

\section{Acknowledgment}

None.

\section{Conflict of Interest}

No conflict of interest.

\section{References}

1. Pugh TWH (2019) Iris Publishers: Open Access Journal of Addiction and Psychology Cultural Addiction and Ritualistic Agreements Regarding Family Engagements, Working Roles and Social Agreements made thereof. Open Access J Addict \& Psychol. 1(4).

2. Kellner D (1995) Routledge: Cultural Studies, Identity and Politics between the Modern and Post-Modern.

3. Editors Encyclopaedia Britannica (2019) Encyclopaedia Britannica $250^{\text {th }}$ (edn): Neurosis Psychology.

4. Bradshaw CP, Lindsey M Oapos, Brennan, Sawyer AL (2018) SAGE Journals: Examining Variation in Attitudes towards Aggressive Retaliation and Perceptions of Safety among Bullies, Victims and Bully/ Victims. 